
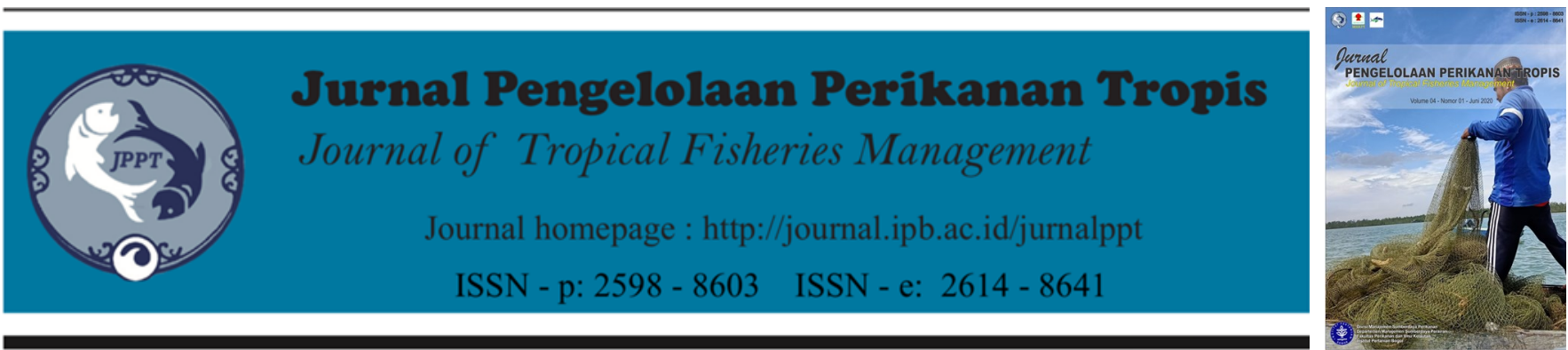

\title{
Hubungan Panjang dan Bobot Bigeye Tuna (Thunnus obesus Lowe, 1839) Di Perairan Samudera Hindia
}

\author{
(Length-Weight Relationship of Bigeye Tuna (Thunnus obesus Lowe, 1839) in Indian Ocean)

\section{Grin Tommy Panggabean ${ }^{1}$, Siti Nurkhotini' ${ }^{2}$ Yonvitner $^{2}$} \\ ${ }^{1}$ Program Studi Pengelolaan Sumberdaya Perairan, Sekolah Pasca Sarjana, Institut Pertanian Bogor. \\ ${ }^{2}$ Departmen Manajemen Sumberdaya Perairan, Fakultas Perikanan dan Ilmu Kelautan, Institut Pertanian Bogor.
}

\section{ARTIKEL INFO}

Article History

Recevied: 11 Mei 2020

Accepted: 16 Juli 2020

\section{Kata Kunci:}

Cicalap, Thunnus obesus, panjang-

bobot, pertumbuhan

\section{Keywords:}

Cicalap, growth, length-weight,

Thunnus obesus

\section{Korespondensi Author}

Grin Tommy Panggabean,

Program Studi Pengelolaan

Sumberdaya Perairan, Fakultas

Perikanan dan Ilmu Kelautan, Institut

Pertanian Bogor. Email:

tommy_123@apps.ipb.ac.id

\begin{abstract}
ABSTRAK
Potensi sumberdaya perikanan di Indonesia sebesar 9,931 juta ton per tahun, dengan potensi tertinggi terdapat di WPP 718 sebesar 1,992 juta ton/tahun (20\%), di WPP 572 sebesar 1,228 juta/tahun (12 \%) dan di WPP 711 sebesar 1,143 juta ton/tahun (12\%). Bigeye Tuna (Thunnus obesus) menjadi salah satu komoditas unggulan dari sub sektor perikanan yang umum dikonsumsi baik skala lokal maupun ekspor. Pelabuhan Perikanan Samudera (PPS) Cilacap, Kabupaten Cilacap, merupakan salah satu pendaratan ikan Bigeye Tuna (Thunnus obesus) yang ditangkap dari Samudera Hindia. Penelitian ini bertujuan untuk mengetahui informasi hubungan panjang bobot Bigeye Tuna (Thunnus obesus) yang ditangkap dari Samudera Hindia dan didarat di PPS Cilacap, Jawa Tengah. Menurut PPS Cilacap (2014), Bigeye Tuna (Thunnus obesus) termasuk jenis ikan pelagis besar yang hasil tangkapan terbanyak setelah ikan cakalang dari keseluruhan ikan yang didaratkan. Sebaran frekuensi panjang tertinggi Bigeye Tuna (Thunnus obesus) yang tertangkap berada disebaran panjang 123,5 $156,5 \mathrm{~cm}$. Hasil anlisis hubungan anjang bobot diperoleh kesimpulan bahwa pola pertumbuhan ikan Bigeye Tuna (Thunnus obesus) adalah allometrik negative $(b<3)$. Dalam biologi perikanan, hubungan panjang bobot ikan ini merupakan salah satu informasi yang perlu diketahui dalam kaitan pengelolaan sumberdaya perikanan.
\end{abstract}

\begin{abstract}
The potential of fisheries resources in Indonesia is 9,931 million tons per year, with the highest potential being in WPP 718 of 1,992 million tons/year (20\%), in WPP 572 of 1,228 million/year (12\%) and in WPP 711 of 1,143 million tons/year (12\%). Bigeye Tuna (Thunnus obesus) is one of the leading commodities from the fisheries sub-sector which is commonly consumed both locally and export. Cilacap Ocean Fishery Port (PPS), Cilacap Regency, is one of the Bigeye Tuna (Thunnus obesus) fish landings caught from the Indian Ocean. This study aims to find out information on the long-weight relationship of Bigeye Tuna (Thunnus obesus) captured from the Indian Ocean and landed at PPS Cilacap, Central Java. According to Cilacap PPS (2014), Bigeye Tuna (Thunnus obesus) is a large pelagic fish species that catches the most after skipjack fish from all landed fish. The highest frequency distribution of Bigeye Tuna (Thunnus obesus) caught is spread between 123.5 $-156.5 \mathrm{~cm}$ length. The results of the analysis of the relationship between weight weights show that the growth pattern of Bigeye Tuna (Thunnus obesus) fish is allometric negative $(b<3)$. In fisheries biology, this long fish weight relationship is one of the information that needs to be known in terms of fisheries resource management.
\end{abstract}

\section{PENDAHULUAN}

Potensi sumberdaya perikanan di Indonesia sebesar 9,931 juta ton per tahun, dengan potensi tertinggi terdapat di WPP 718 sebesar 1,992 juta ton/tahun (20\%), di WPP 572 sebesar 1,228 juta/ tahun (12\%) dan di WPP 711 sebesar 1,143 juta ton/tahun (12\%). Komposisi sumber daya ikan di Indonesia umumnya didominsasi oleh kelompok ikan pelagis kecil dan besar dengan persentase pelagis kecil sebesar $36 \%$ dan ikan pelagis besar sebesar $25 \%$. Menurut data statistik perikanan, hasil tangkapan kelompok tuna di Indonesia mencapai 1,297 juta ton dari tahun 2004 hingga 2011. Dari total tangkapan kelompok tuna tersebut, produksi ikan Bigeye Tuna merupakan kedua tertinggi yaitu sebesar $24 \%$, sedang yang paling tinggi adalah madidihang sebesar $69 \%$, sisanya adalah albakora sebesar $6 \%$ dan tuna sirip biru selatan kurang dari 1\% dari total produksi kelompok tuna besar (DJPT 2012). 
Ikan Bigeye Tuna atau Bigeye Tuna (Thunnus obesus) merupakan ikan pelagis besar yang memiliki sifat migrasi jauh (highly migratory species) dan penyebarannya di perairan tropis dan perairan subtropis. Bigeye Tuna dapat ditemukan di Samudera Atlantik, Hindia dan Pasifik (Collette dan Nauen 1983). Di Indonesia, daerah penyebaran Bigeye Tuna meliputi perairan barat dan selatan Sumatra (Jatmiko et al. 2014), Teluk Tomini (Mardlijah dan Rahmat 2012), selatan Jawa, Bali dan Nusa Tenggara, Laut Banda dan sekitarnya, Laut Sulawesi dan perairan barat Papua (Uktolseja et al. 1991). Bigeye Tuna menyukai suhu air antara $17^{\circ} \mathrm{C}$ dan $22^{\circ} \mathrm{C}$. Pepperell (2010) melaporkan bahwa Bigeye Tuna lebih suka tinggal di dekat dan biasanya di bawah lapisan termoklin dan dapat membuat gerakan vertikal secara berkala. Kisaran kedalaman penangkapan ikan untuk Bigeye Tuna di Samudra Hindia adalah 161-280 m (Mohri dan Nishida 1999). Namun, mereka dapat muncul ke permukaan pada kedalaman 0 $100 \mathrm{~m}$ pada malam hari (Howell et al. 2010). Selain itu, Sukresno et al. (2015) dan Hartoko (2010) menunjukkan bahwa Bigeye Tuna lebih memilih untuk tetap di kedalaman sekitar $150 \mathrm{~m}$. Oleh karena itu, dalam penelitian ini, kami fokus pada cara-cara di mana karakteristik area penangkapan Bigeye Tuna pada kedalaman 155 $\mathrm{m}$.

Bigeye Tuna (Thunnus obesus) menjadi salah satu komoditas unggulan dari sub sektor perikanan yang umum dikonsumsi baik skala lokal maupun ekspor. Pelabuhan Perikanan Samudera (PPS) Cilacap, Kabupaten Cilacap, merupakan salah satu pendaratan ikan Bigeye Tuna (Thunnus obesus) yang ditangkap dari
Samudera Hindia. Selama kurun waktu 10 tahun pada tahun 2005 sampai 2014 mencapai 2.015.153 ton dengan rata-rata 201.515 ton/tahun, dimana persentase hasil tangkapan madidihang (Thunnus albacares) mendominasi yang diperkirakan mencapai $69,5 \%$ dari total hasil tangkapan. Selanjutnya, hasil tangkapan diikuti oleh Bigeye Tuna (Thunnus obesus) sebanyak 25\%, tuna albakora (Thunnus alalunga) 5\% dan tuna sirip biru (Thunnus maccoyii) sebesar 0,5\% (DJPT 2012). Hal ini membuat penangkapan secara terus menerus dapat menurunkan stok ikan.

Analisis panjang-berat ikan sangat penting diketahui untuk mengetahui kondisi biologi ikan dan stok ikan agar mudah dilakukan manajemen keberlangsungan biodiversitas ikan (Froese 2006; Rosli dan Isa 2012). Selain itu, analisis panjangberat ikan dijadikan sebagai indikator biologi dari kondisi ekosistem perairan (Courtney et al. 2014). Dalam biologi perikanan, hubungan panjang berat ikan merupakan salah satu informasi yang perlu diketahui dalam kaitan pengelolaan sumberdaya perikanan. Penelitian ini bertujuan untuk mengetahui informasi hubungan panjang berat ikat Bigeye Tuna (Thunnus obesus) yang ditangkap dari Samudera Hindia dan didarat di PPS Cilacap, Jawa Tengah.

\section{METODE}

\section{Lokasi dan Waktu Penelitian}

Penelitian ini telah dilakukan PPS Cilacap, Jawa Tengah dan pengambilan contoh ikan dialakukan pada bulan Desember 2014 sampai dengan Maret 2015 dengan interval waktu lebih kurang selama 30 hari. Contoh ikan yang diambil

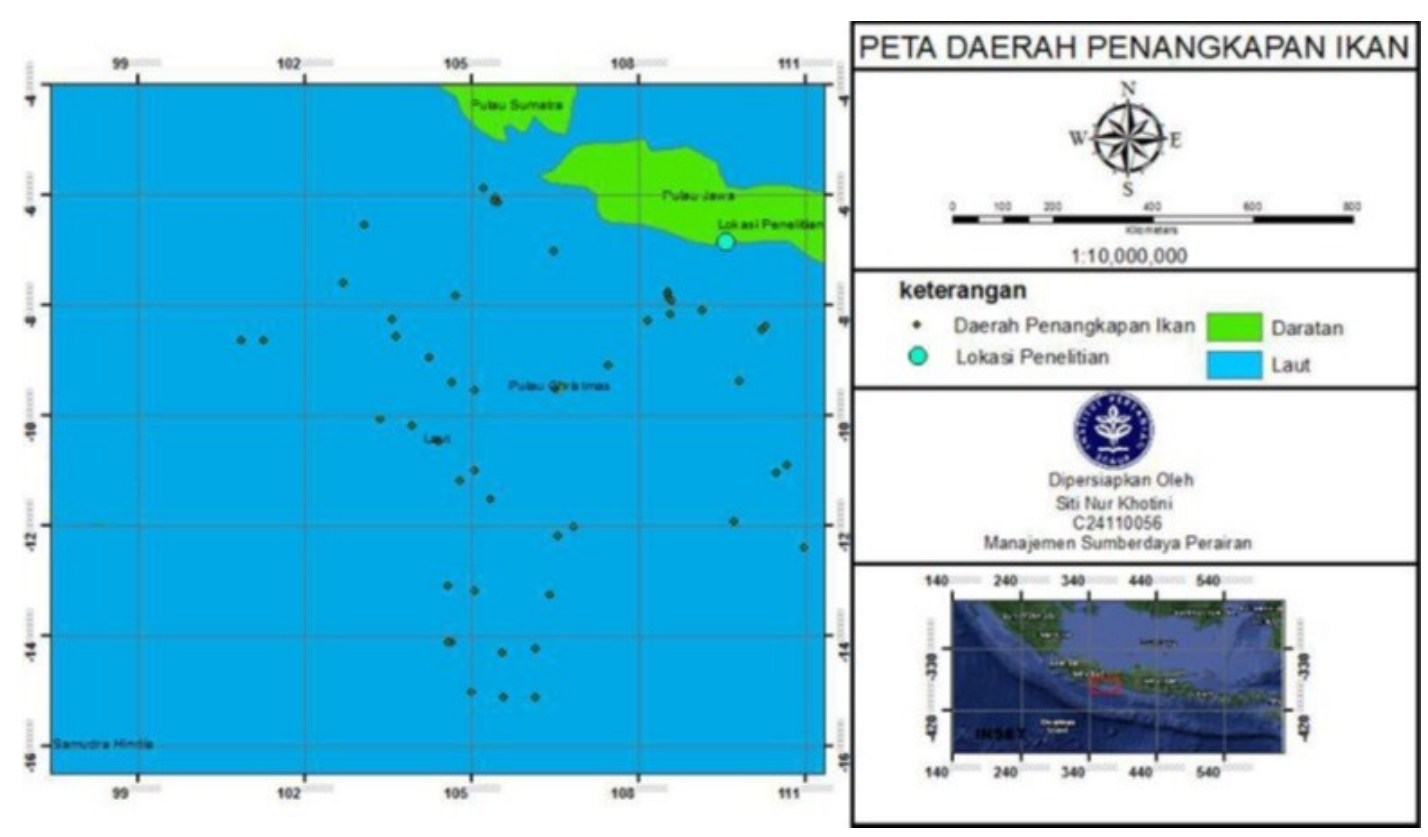

Gambar 1. Lokasi penelitian di PPS Cilacap, Jawa Tengah dan daerah penangkapan ikan di Perairan Samudera Hindia 
adalah ikan yang ditangkap diperairan Samudera Hinda (WPP 573) dengan dasar informasi titik penangkapan nelayan dan hasilnya didaratkan di PPS Cilacap (Gambar 1).

\section{Pengumpulan Data}

Data yang diteliti terdiri dari data primer dan data sekunder, yaitu panjang dan berat ikan (data primer) dan komposisi hasil tangkapan tahun 2010 hingga 2014 di PPS Cilacap, Jawa Tengah (data sekunder). Data primer berupa data panjang Bigeye Tuna (Thunnus obesus) yang berjumlah 1549 ekor dengan metode Penarikan Contoh Acak Sederhana (PCAS). Panjang Bigeye Tuna (Thunnus obesus) yang diukur adalah panjang cagak yaitu pengukuran dari ujung mulut ikan sampai dengan pangkal ekor menggunakan alat ukur panjang dengan skala terkecil $1 \mathrm{~cm}$.

\section{Analisis Data}

\section{Distribusi frekuensi panjang}

Distribusi frekuensi menggunakan data kelompok. Pertama mencari banyaknya jumlah data (n), nilai panjang total maksimum, dan panjang total minimum. Setelah itu mencari jumlah kelas, interval kelas, dan jarak kelas dengan rumus sebagai berikut:

$$
\begin{aligned}
& \text { Jumlah kelas }=1+3,32 \log (\mathrm{n}) \\
& \text { Interval kelas }=\frac{\text { Maksimum }- \text { Minimum }}{\text { Jumlah Kelas }} \\
& \text { Jarak Kelas }=\text { Interval kelas }+ \text { nst } \\
& \text { setelah itu membuat tabel sebaran frekuensi dan } \\
& \text { diagram batang panjang total ikan. }
\end{aligned}
$$

\section{Hubungan panjang bobot}

Panjang dan bobot ikan merupakan peta data dasar yang dingunakan menjadi varibel pengelolaan sumberdaya ikan. Analisis hubungan panjang bobot masing-masing spesies ikan menggunakan formula sebagai berikut (Effendie 2002):

$$
\begin{gathered}
W=a L^{b} \\
\log W=\log a+b \log L
\end{gathered}
$$

Dimana:

$$
\begin{array}{ll}
\mathrm{W} & =\text { berat ikan }(\text { gram }) \\
\mathrm{L} & =\text { panjang ikan }(\mathrm{mm}) \\
\mathrm{a}, \mathrm{b} & =\text { konstanta }
\end{array}
$$

Pertumbuhan pada ikan terdapat dua pola yaitu yang pertama pertumbuhan isometrik $(n=3)$ dimana pertambahan hubungan panjang berat ikan seimbang dan yang kedua pertumbuhan allometrik $(\mathrm{n}>3$ atau $\mathrm{n}<3)$, dimana $\mathrm{n}>3$ menunjukkan ikan itu gemuk/ montok dan pertambahan berat lebih cepat dari pertambahan panjangnya (alometerik negatif), sedangkan $n<3$ menunjukkan ikan dengan kategori kurus, dimana pertambahan panjang lebih cepat dari pertambahan berat (allometrik posistif) (Effendie 2002).

\section{HASIL DAN PEMBAHASAN}

\section{Hasil}

Komposisi hasil tangkap perikanan di PPS Cilacap

Pelabuhan Perikanan Samudera (PPS) Cilacap terletak di Desa Tegalkamulyan, Kecamatan Cilacap Selatan, Kabupaten Cilacap, Provinsi Jawa Tengah. PPS Cilacap merupakan

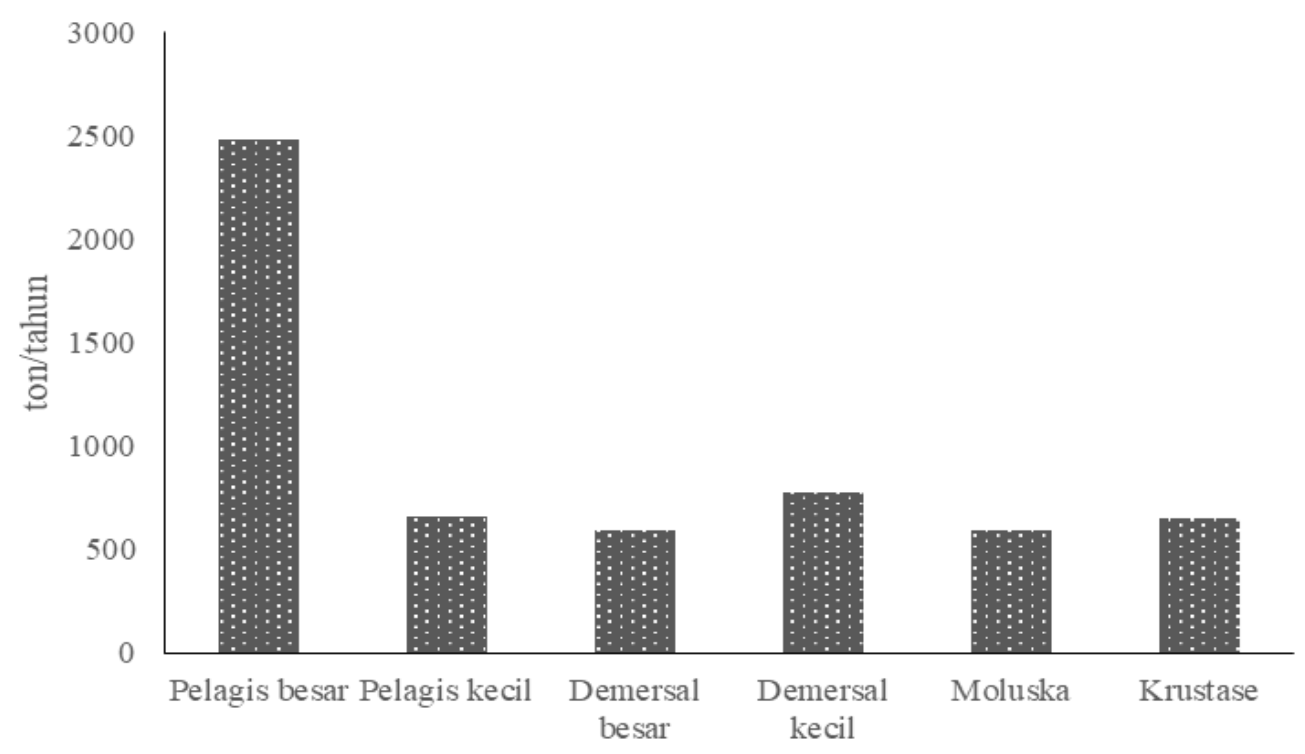

Gambar 2. Komposisi hasil tangkapan di PPS Cilapcap, Jawa Tengah 
salah satu tempat ikan di Jawa Tenga dengan daerah penangkapan terbesar berada di pantai selatan Jawa serta berhadapan langsung dengan Samudera Hindia (WPP 573). Produksi perikanan yang didaratkan di PPS Cilacap terdiri dari ikan pelagis, demersal, moluska dan krustase. Ratarata hasil tangkapan dari tahun 2010 hingga 2014 yaitu $3.290,5$ ton ikan/tahun. Data hasil tangkapan jenis ikan yang didaratkan di pelabuhan didominasi oleh ikan pelagis besar dibandingkan pelagis kecil, ikan demersal kecil maupun besar, moluska dan krustase (Gambar 2).

Menurut PPS Cilacap (2014), ikan Bigeye Tuna (Thunnus obesus) termasuk jenis ikan pelagis besar yang hasil tangkapan terbanyak setaelah ikan Cakalang dari keseluruhan ikan yang didaratkan. Ikan Bigeye Tuna (Thunnus obesus) merupakan ikan dengan tangkapan, yaitu mencapai $23 \%$ atau senilai 390,15 ton dari keseluruhan ikan pelagis besar. Informasi mengenai komposisi hasil tangkapan ikan Bigeye
Tuna (Thunnus obesus) di PPS Cilacap disajikan di Gambar 3.

\section{Sebaran frekuensi panjang dan identifikasi kelompok umur}

Sebaran frekuensi panjang digunakan untuk mengetahui komposisi sebaran berdasarkan pengelompokan panjang ikan. Sebaran frekuensi panjang ikan tertngi Bigeye Tuna (Thunnus obesus) yang tertangkap berada disebaran panjang 123,5 - 156,5 cm. Sebaran frekunsi tersebut dingunakan sebagai data untuk pengeloaan keberlajutan pengkapan ikan (Gambar 4).

\section{Hubungan panjang dan bobot}

Hasil analisis hubungan panjang dan bobot ikan Bigeye Tuna (Thunnus obesus) didapatkan persamaan $\mathrm{W}=0,00005 \mathrm{~L}^{2,9151}$. Pola pertumbuhan ikan Bigeye Tuna (Thunnus obesus) diperoleh setelah mendapatkan persamaan yang kemudian dilakukan uji t. Hasil uji t diperoleh kesimpulan



Gambar 3. Komposisi hasil tangkapan ikan Bigeye Tuna (Thunnus obesus)

Sumber: PPS Cilacap



Gambar 4. Sebaran frekuensi panjang Bigeye Tuna (Thunnus obesus) 


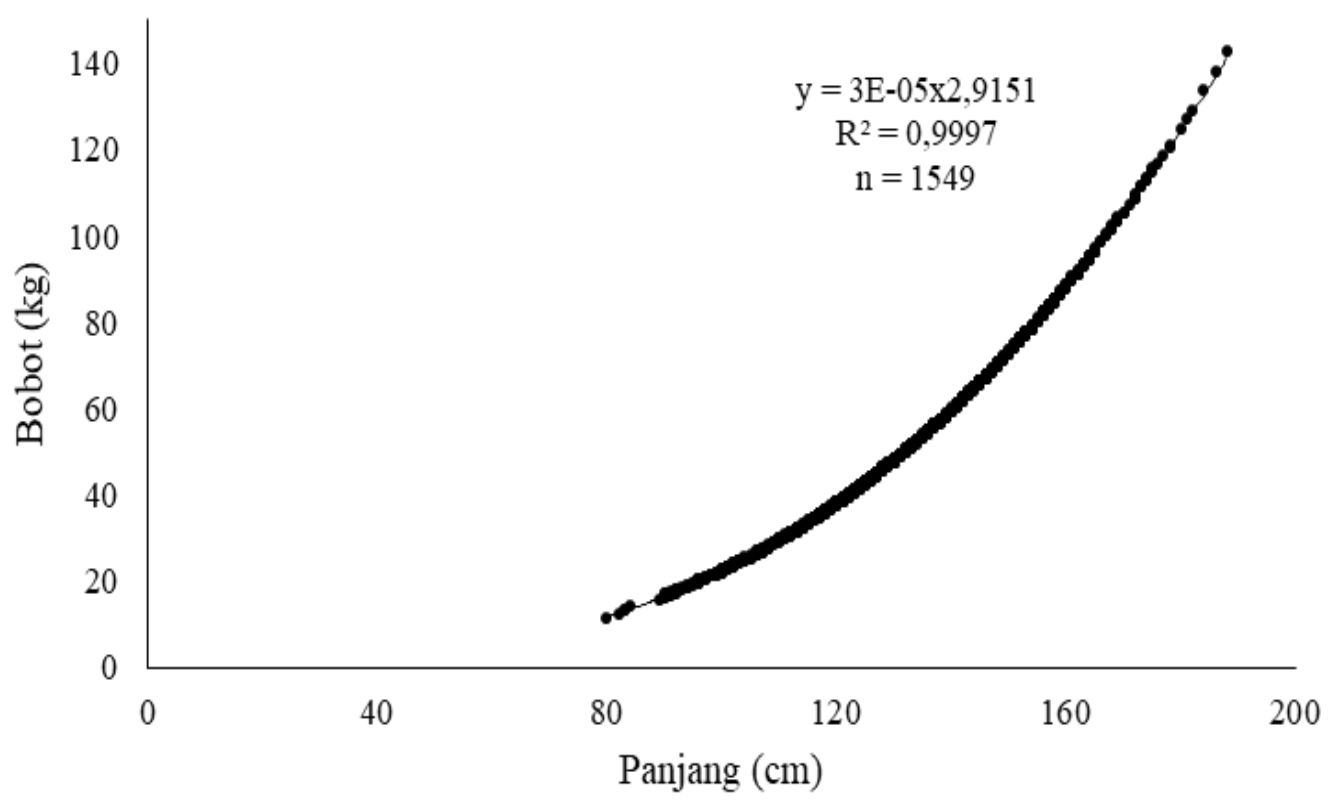

Gambar 5. Hubungan panjang dan bobot Thunnus obesus

bahwa pola pertumbuhan ikan Bigeye Tuna (Thunnus obesus) adalah allometrik negative $(b<3)$. Hal ini berarti pertambahan panjang ikan Bigeye Tuna (Thunnus obesus) lebih cepat dibandingkan pertambahan bobot. Infomasi hubungan panjang dan bobot ikan Bigeye Tuna (Thunnus obesus) disajikan pada Gambar 5.

\section{Pembahasan}

Perikanan merupakan sumberdaya yang bersifat open access, sehingga setiap orang berhak mengeksploitasi sumber daya hayati perikananan (Sobari 2003). Pelabuhan Perikanan Samudera (PPS) Cilacap, Kabupaten Cilacap, merupakan salah satu tempat dimana sumberdaya perikanan tersebut dikumpulkan dan kemudian di distribusikan, sehingga terdapat banyak komposisi jenis ikan yang tertangkap dan berada di PPS Cilcap. Berdasarkan hasil data sekunder ikan yang didaratkan didominasi oleh ikan pelagis besar dibandingkan pelagis kecil, ikan demersal kecil maupun besar, moluska dan krustase. Menurut Zhu et al. (2010) ikan pelagis besar merupakan ikan migrasi sehingga sering ditemukan diperairan samudera. Hal ini sesuai dengan daerah penangkapan para nelayan yang mendaratkan ikannya di PPS Cilacap merupakan perairan selatan jawa yang merupakan perairan samudera hindia.

Perairan Indonesia memiliki keanekaragaman sumber daya ikan pelagis besar yang tinggi, karakteristik oseanografi yang unik dan dinamis (Susanto et al. 2006), karena Perairan Indonesia juga dipengaruhi oleh fenomena Monsun AsiaAustralia (Longhurst 2007), aliran Indonesia Through (Wijffels et al. 2008) dan El Nino Southern Oscillation (ENSO) (Hendiarti et al.
2005). Salah satu perairan Indonesia yang terkenal sebagai daerah penangkapan ikan adalah perairan selatan Jawa - kepulauan Nusa Tenggara Sumatera (Hendiarti et al. 2005). Wilayah ini terkenal sebagai daerah penangkapan ikan untuk ikan yang penting secara ekonomi seperti Bigeye tunas (Thunnus obesus). Berdasarkan hasil yang didapat dimana komposisi Bigeye Tuna (T. Obesus) merupakan ikan dengan tangkapan mencapai $23 \%$ atau senilai 390,15 ton dari keseluruhan ikan pelagis besar, sehingga perairan laut selatan jawa yang merupakan perairan samudera hindia merupakan wilayah postensi Bigeye Tuna (T. obesus).

Pengolahan ikan tersebut mempunyai konsekuensi dalam penurunan berat badan ikan. Ekspoloitasi yang terus menerus merupakan faktor yang mempengaruhi hal tersebut. Bigeye Tuna (Thunnus obesus) merupakan ikan salah satu ikan ekonomis yang dikomsumsi di Indonesia. Hal ini membuat Bigeye Tuna (Thunnus obesus) menjadi target ikan tangkapan nelayan. Sehingga penelitian mengenai hubungan panjang berat penting dilakukan untuk menjadi dasar data pengelolaan. Hubungan berat-berat dan panjang-beratnya adalah studi hubungan penting untuk perikanan manajemen, misalnya dalam menghitung hasil dan biomassa (King 2007). Berdarkan penelitian ( Sun et al. 2001; Zhu et al. 2008; Faizah dan Prisantoso 2010; Riswanto 2012) mengatakan pola pertumbuhan dari ikan Bigeye Tuna (Thunnus obesus) adalah allometrik negatif dan berdasarkan penelitian ini ikan Bigeye Tuna (Thunnus obesus) yang didaratkan di PPS Cilacap, Jawa Tegah juga allometrik negatif berdarkan nilai $b<3$. Perubahan nilai $b$ ini kemungkinan disebabkan ketersediaan sumber makanan dan kondisi lingkungan yang berbeda 
(Froese 2006), aktivitas berenang ikan, jenis kelamin (Kunzmann and Braitmaier 2018) serta faktor lainnya seperti perilaku ikan (Mulfizar et al. 2012).

Sebaran frekuensi panjang ikan Bigeye Tuna (Thunnus obesus) yang didaratkan di PPS Cilapcap perlu untuk mengetahui apakah terjadi perubahan ukuran dari Bigeye Tuna (Thunnus obesus. Penelitian Nootmorn (2004) ikan Bigeye Tuna dari Samudera Hindia yang tercatat di Phuket, Tahiland yaitu berkisar antara $85-155 \mathrm{~cm}$ dan menurut penelitian Faizah dan Prisantoso (2010) sebelah selatan Jawa Timur sampai Nusa Tenggara diperoleh ukuran Bigeye Tuna berkisar antara 98-153 cm dan pada penelitian ini berada di kisaran 90,5- 189,5 cm. Berdasarkan penelitian tersebut dapat disimpulkan penangkapan ikan Bigeye Tuna (Thunnus obesus) berada dikisaran yang sama dan pada kondisi yang tidak berubah dari tahun 2004 sampai 2015.

Dalam biologi perikanan, hubungan panjang bobot ikan merupakan salah satu informasi yang perlu diketahui dalam kaitan pengelolaan sumberdaya perikanan. Pertumbuhan ikan sangat penting untuk mengetahui kondisi biologi ikan dan stok, sehingga menajdi dasar manajemen keberlangsungan biodiversitas ikan (Froese 2006). Peta informasi dasar perlu diketaui untuk pengelolaan sumberdaya ikan selanjutnya, misalnya dalam menghitung biomassa. Data informasi ikan Bigeye Tuna (Thunnus obesus) perlu untuk menunjang pengelolaan yang berkelanjutan sehingga kebutuhan komsumsi akan ikan Bigeye Tuna (T. obesus) dapat terpenuhi.

\section{KESIMPULAN}

Hubungan panjang berat ikan Bigeye Tuna (Thunnus obesus) yang ditangkap dari Samudera Hindia dan didarat di PPS Cilacap, Jawa Tengah memiliki pola alometrik negatif, dengan sebaran frekunsi panjang yang tertangkap adalah kisaran 90,5- 189,5 cm. Kondisi ini belum terjadi perubahan dari penelitian terdahulu sehingga potensi ikan Bigeye Tuna (Thunnus obesus) masih dalam kondisi stabil.

\section{DAFTAR PUSTAKA}

Collete HB, Nauen CE. 1983. Scombridae of the world, an annotated and illustrated catalogue of tunas, mackerels, bonitos and related species known to date. Species Catalogue Vol. 2. FAO. $137 \mathrm{pp}$.

Courtney Y, Courtney J, Courtney M. 2014. Improving weight-length relationship in fish to provide more accurate bioindicators of ecosystem condition. J. Aquatic Science and Technology. 2(2).

Direktorat Jenderal Perikanan Tangkap (DJPT).
2012. Statistik Perikanan Tangkap Indonesia 2011. Jakarta (ID): Kementerian Kelautan dan Perikanan.

Effendie MI. 2002. Biologi Perikanan. Yogyakarta (ID): Yayasan Pustaka Nusatama.

Faizah R, Prisantoso IB. 2010. Biologi reproduksi tuna mata besar (Thunnus obesus) yang tertangkap di Samudera Hindia. Bawal. 3(2): 183-189.

Froese R. 2006. Cube law, condition factor and weight-length relatoinship: history, metaanalysis and reccomendations. J. Appl. Ichthyol. 22:241-253.

Hartoko A. 2010. Spatial distribution of Thunnus sp., vertical and horizontal sub-surface multilayer temperature profiles of in-situ agro float data in Indian Ocean. $J$ Coastal Development. 14:61-74.

Hendiarti N, Suwarso, Aldrian E, Amri K, Andiastuti R, Sachoemar SE, Wahyono IB. 2005. Pelagic fish catch around Java. Oceanography. 18(4):112-123.

Howell EA, Hawn DR, Polovina JJ. 2010. Spatio temporal variability in bigeye tuna (Thunnus obesus) dive behavior in the central North Pacific Ocean. Prog. Oceanogr. 86:81-93.

Jatmiko I, Setyadji B, Novianto D. 2014. Distribusi spasial dan temporal ikan tuna mata besar (Thunnus obesus) di Samudra Hindia bagian timur. J. Lit Perikan. Ind. 20 (3):137-142.

King M. 2007. Fisheries Biology, Assessment and Management, Second Edition. Oxford (UK): Blackwell Publishing.

Kunzman A, Braitmaier M. 2018. Length-weight relationships of fourcommercially important fish species in Indonesia. Annual Research \& Reviewin Biology. 24(4): 1-9.

Longhurst AR. 2007. Ecological Geography of the Sea. Second Edition. Amsterdam: Elsevier.

Mardlijah S, Rahmat E. 2012. Penangkapan juvenile ikan madidihang (Thunnus albacares Bonnatere 1788) di perairan Teluk Tomini. Bawal. 4(3): 169-176.

Mohri M, Nishida T. 1999. Distribution of bigeye tuna (Thunnus obesus) and its relationship to the environmental conditions in the Indian Ocean based on the Japanese longline fisheries information. IOTC Proceedings. 2: 221-230.

Mulfizar, Muchlisin ZA, Dewiyanti I. 2012. Hubungan panjang berat dan faktor kondisi tiga jenis ikan yang tertangkap di perairan Kuala Gigieng, Aceh Besar, Provinsi Aceh. Depik. 1(1): 1-9.

Nootmorn P. 2004. Reproductive biology of big eye tuna in the eastern Indian ocean. Indian Ocean Tuna Commission Proceedings. 7: 1-5. 
Pepperell J. 2010. Fishes of the Open Ocean: A Natural History and Illustrated Guide. Chicago (US): University of Chicago Press.

Riswanto S. 2012. Status perikanan tuna mata besar (Thunnus obesus, Lowe1839) di Perairan Samudera Hindia, Selatan Palabuhanratu, Sukabumi [tesis]. Depok (ID): Universitas Indonesia.

Rosli NAM, Isa MM. 2012. Length-weight and length-length relationship of longsnouted catfish, Plicofollis argyropleuron (Valenciennes, 1840) in the Northern Part of Peninsular Malaysia. Journal Tropical Life Sciences Research. 23(2): 59-65.

Sobari MP, Kinseng RA, Priyatna FN. 2003. Membangun model pengelolaan sumber daya perikanan berkelanjutan berdasarkan karakteristik sosial ekonomi masyarakat nelayan: tinjauan sosiologi antroplogi. Bulletin Ekonomi Perikanan. 5(1): 41-48.

Sukresno B, Hartoko A, Sulistyo B, Subiyanto. 2015. Empirical Cumulative Distribution Function (ECDF) Analysis of Thunnus.sp using ARGO Float Sub-surface Multilayer Temperature Data in Indian Ocean South of Java. Procedia Environmental Sciences. 23: 358-367.

Sun CL, Huang CL, Yeh SZ. 2001. Age and growth of the bigeye tuna, Thunnus obesus, in the western Pacific Ocean. Fisheries Bulletin. 99(3): 502-509.

Susanto RD, Moore IITS, Marra J. 2006. Ocean Color Variabilty in The Indonesia Seas during SeaWiFS Era. Geochemistry, Geophysics and Geosystems. 7(5): 22-35.

Uktolseja JCB, Gafa B, Bahar S. 1991. Potensi dan penyebaran sumber daya ikan tuna dan cakalang. In: Martosubroto P, Naamin N, Malik BBA (eds.). Potensi dan Penyebaran Sumber daya Ikan Laut di Perairan Indonesia. Jakarta (ID): Direktorat Jenderal Perikanan. Pusat Penelitian dan Pengembangan Perikanan. Pusat Penelitian dan Pengembangan Oseanologi. Jakarta. 29$43 \mathrm{pp}$.

Wijffels SE, Meyers G, Godfrey JS. 2008. A 20Yr Avarage of the Indonesia Troughflow: Regional Currents and Interbasin Exchange. Journal of Physical Oceanography. 38: 19651978.

Zhu G, Xu L, Zhou Y, Dai X. 2008. Length frequency compositions and weightlength relations for Bigeye tuna, Yellowfin tuna and Albacore (Perciformes: Scombridae) in the Atlantik, Indian, and Eastern Pasific Oceans. AcatIchthiological Et Piscatoria. 38(2): 157161.

Zhu GP, Xu LX, Zhou YQ, Song LM, Dai XJ. 2010. Length-weight relationships for bigeye tuna (Thunnus obesus), yellowfin tuna
(Thunnus albacares) and albacore (Thunnus alalunga) (Perciformes: Scombrinae) in the Atlantic, Indian and Eastern Pacific Oceans. Collect. Vol. Sci. Pap. ICCAT. 65(2): 717724. 